Revista Brasileira de Farmacognosia Brazilian Journal of Pharmacognosy 21(6): 1138-1143, Nov./Dec. 2011

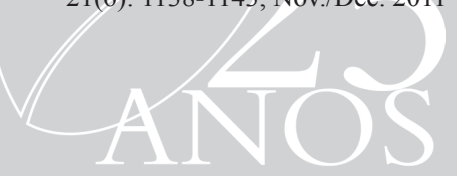

Article

Received 2 Aug 2010 Accepted 25 Apr 2011

Available online 26 Aug 2011

Keywords:

p-cymene

antinociception

orofacial nociception

formalin

capsaicin

glutamate

ISSN 0102-695X

http://dx.doi.org/10.1590/S0102-

695X2011005000156

\section{$p$-Cymene reduces orofacial nociceptive response in mice}

\author{
Michele F. Santana, Lucindo J. Quintans-Júnior, Sócrates $C$. \\ H. Cavalcanti, Makson G. B. Oliveira, ${ }^{1}$ Adriana G. Guimarães, \\ Edisleide S. Cunha, Mônica S. Melo, Márcio R. V. Santos, \\ Adriano A. S. Araújo, Leonardo R. Bonjardim*
}

Departamento de Fisiologia, Universidade Federal de Sergipe, Brazil.

\begin{abstract}
This study investigated the possible antinociceptive effect of $p$-cymene in different tests of orofacial nociception. The animals (mice) were pretreated (i.p.) with $p$-cymene $(25,50,100 \mathrm{mg} / \mathrm{kg})$, morphine $(5 \mathrm{mg} / \mathrm{kg})$, or vehicle $(0.2 \%$ Tween $80+$ saline), and were then subsequently administered, subcutaneously into their upper lip: formalin, capsaicin, and glutamate. The nociceptive behavior response was characterized by the time in s that the mice remained rubbing the orofacial region, for a period of $40 \mathrm{~min}$ in the formalin test (first phase, 0-6 min; and second phase, 21-40 min), and for 42 and $15 \mathrm{~min}$ in the capsaicin and glutamate tests, respectively. To verify the possible opioid involvement in the antinociceptive effects, naloxone (i.p.) was administered into the mice $15 \mathrm{~min}$ prior to the pretreatment with $p$-cymene $(100 \mathrm{mg} / \mathrm{kg})$. Finally, whether or not the $p$-cymene evoked any change in motor performance in the Rota-rod test was evaluated. The results showed that the treatment with $p$-cymene, at all doses, reduced $(p<0.001)$ the nociceptive behavior in all nociception tests. The antinociceptive effect of $p$-cymene was antagonized by naloxone $(1.5 \mathrm{mg} / \mathrm{kg})$. Additionally, mice treated with $p$-cymene did not show any change in motor performance. In conclusion, $p$-cymene attenuated orofacial nociception, suggesting an involvement of the opioid system in this effect. Thus, $p$-cymene might represent an important biomolecule for management and/or treatment of orofacial pain.
\end{abstract}

\section{Introduction}

Orofacial pain accounts for over $25 \%$ of all complaints in respect to pain (Sessle, 1987). Orofacial pain refers to conditions related to oral and face structures (Lipton et al., 1993), and stands out from other somatic pain due to its high intensity and prevalence, which often prevents an individual from performing his/her daily activities normally (Barros et al., 2009).

A variety of drugs are used for the pharmacological treatment of orofacial pain, such as the opioid and non-opioid analgesics, non-steroidal anti-inflammatory drugs (NSAID), corticosteroids, anxiolytics, antidepressants, and anticonvulsants (Dionne, 2001), but the side effects and high costs of these drugs have led to a constant search for alternative drugs from medicinal plants with analgesic and antiinflammatory properties.

$p$-Cymene ( $p$-isopropyltoluene, $\mathbf{1})$ is a monoterpene biological precursor of carvacrol and one of the main constituents of the essential oil from species of Protium, with more than $80 \%$ of these species found in the Amazon region (Siani et al., 1999). Recent studies have shown that species such as Protium heptaphyllum (Aubl.) Marchand, P. kleinii Cuatrec., Burseraceae, Hyptis pectinata (L.) Poit., Lamiaceae and Zataria multiflora Boiss., Lamiaceae, rich in $p$-cymene, show antinociceptive activity in rodents (Oliveira et al., 2005; Otuki et al., 2001; Bispo et al., 2001; Ramezani et al., 2004).<smiles>Cc1ccc(C(C)C)cc1</smiles>

In addition, other monoterpenes such as menthol, linalool, citronellal, and carvone have shown antinociceptive activity in animal models of nociception (Melo et al., 2010; Galeotti et al., 2002; Peana et al., 2006; Gonçalves et al., 2008; Quintans-Júnior et al., 
2010).

Since $p$-cymene-containing natural products and others monoterpenes have been used by to alleviate pain and inflammation-related processes it is believed that $p$-cymene can be an effective agent in the management of orofacial pain. With this in mind, this study investigated the antinociceptive potential of $p$-cymene in models of orofacial nociception induced by formalin, capsaicin, and glutamate.

\section{Material and Methods}

\section{Drugs}

For the experiments the following drugs were used: $p$-cymene (99.7\% purity; Sigma, USA), morphine hydrochloride (Merck, Brazil), naloxone (Res. Biochemicals Inc., USA), formaldehyde PA (Reagen, Brazil), capsaicin (Sigma, USA), diazepam (União Química, Brazil). Vehicle was $0.2 \%$ Tween 80 (Sigma, USA) dissolved in saline.

\section{Animals}

The experiments were performed with male Swiss mice (25-30 g), from the Central Animal Facility of the Federal University of Sergipe. The animals were kept four to five per cage $(41 \times 34 \times 18 \mathrm{~cm})$, at a temperature of $22-24{ }^{\circ} \mathrm{C}$, in a light controlled room $(12 \mathrm{~h} / 12 \mathrm{~h}$ light/ dark cycle, lights on at 6:00 a.m.), with water and food ad libitum. All procedures were in compliance with the guidelines of the International Association for the Study of Pain (IASP) (Zimmermann, 1983) and were approved by the Ethics Committee on Animal Care at UFS (Protocol $N^{\circ}$ 03/2009).

\section{Experimental nociceptive tests}

Formalin test

The induction of nociception in the orofacial formalin test was done by subcutaneous injection of formalin $(20 \mu \mathrm{L}, 2 \%)$ into the upper lip of mice $(n=8 /$ group) according to previous studies (Luccarini et al., 2006). The administration of formalin in the orofacial region induces a biphasic behavioral response (Cadet et al., 1993). The first phase (Phase 1) occurs within 0-5 min after administration of the nociceptive substance; this phase is followed by a latency period of about $10 \mathrm{~min}$. Then, a second phase (Phase 2) occurs with duration of about $25 \mathrm{~min}$ (15 to $40 \mathrm{~min}$ ). The nociceptive behavior assessed during the two phases was the time that the animals remained rubbing the orofacial region.

The animals were pretreated systemically (intraperitoneal route) with vehicle $(0.2 \%$ Tween
$80+$ saline $), p$-cymene $(25,50,100 \mathrm{mg} / \mathrm{kg})$, and morphine $(5 \mathrm{mg} / \mathrm{kg}) 30 \mathrm{~min}$ before injection of formalin. The possible involvement of the opioid system in the antinociception produced by $p$-cymene was tested by administration of naloxone $(1.5 \mathrm{mg} / \mathrm{kg})$, an opioid antagonist, $30 \mathrm{~min}$ before administration of the above mentioned drugs.

\section{Capsaicin test}

This orofacial nociception test was induced by subcutaneous administration of capsaicin as described previously by Pellisier (Pellisier et al., 2002). Mice $(n=8)$ received a subcutaneous injection of capsaicin (20 $\mu \mathrm{L}, 2.5 \mu \mathrm{g}$ diluted in DMSO 25\% in distilled water) into the upper lip. In pilot studies performed in our laboratory, the animals showed the behavior of rubbing the orofacial region with greater intensity for a period of 42 min after the injection of capsaicin. Therefore, the quantification of nociception was performed during this period, measuring the time (s) that the animals exhibited the nociceptive behavior of rubbing the orofacial region with the hind or front paw. The $p$-cymene, morphine, and vehicle were administered in a similar manner and at the same doses as the previous test.

\section{Glutamate test}

This orofacial nociception test was induced by subcutaneous administration of glutamate into the upper lip of mice as described previously by Quintans-Júnior et al. (2010). Mice were divided into five groups $(n=8)$ and treated intraperitoneally with vehicle, $p$-cymene $(25,50,100 \mathrm{mg} / \mathrm{kg})$, or morphine $30 \mathrm{~min}$ before the injection of $40 \mu \mathrm{L}$ of a glutamate $(25 \mathrm{mM})$ solution in the upper lip. Then, the animals were observed for a period of $15 \mathrm{~min}$, starting immediately after the injection of the glutamate. The quantification of nociceptive response was performed during this period, measuring the time (s) that the animals exhibited the behavior of rubbing the orofacial region with the hind or front paw.

\section{Motor performance test}

\section{Rota-rod test}

To assess the possible interference of $p$-cymene on animal motor performance, the rota-rod test was performed. Initially, the mice able to stay on the rotarod for more than $180 \mathrm{~s}$ (7 rpm) were selected $24 \mathrm{~h}$ before the experiment. Then, the animals were divided into five groups $(n=8)$, with which we performed the following treatments: $p$-cymene $(25,50,100 \mathrm{mg} / \mathrm{kg}$, i.p.), vehicle (control), and diazepam (1.5 mg/kg, i.p.); 
after 30,60, and 120 min each animal was submitted to the rota-rod and the results are expressed as the time (s) the animals remained on the rotating rod after the treatments mentioned above. The maximum time of permanence of the animal on the rota-rod was $180 \mathrm{~s}$.

\section{Statistical analysis}

Data were analyzed using GraphPad Prism 3.0 Software. Analysis of variance (ANOVA) was performed, followed by Dunnet's and Tukey's posttest to determine, respectively, which doses differed statistically from the control group and among them. For all tests the level of significance was set at $5 \%$.

\section{Results}

\section{Formalin test}

The results showed that pretreatment with $p$-cymene (at all doses tested) and morphine produced antinociception, evidenced by a statistically significant difference $(p<0.001)$ for the time that the animal remained rubbing the orofacial region, in both phases of testing (Figure 1). It was also demonstrated that naloxone $(1.5 \mathrm{mg} / \mathrm{kg}$, i.p. $)$ reversed the antinociception induced by morphine and $p$-cymene $(100 \mathrm{mg} / \mathrm{kg})$ in both phases of testing.
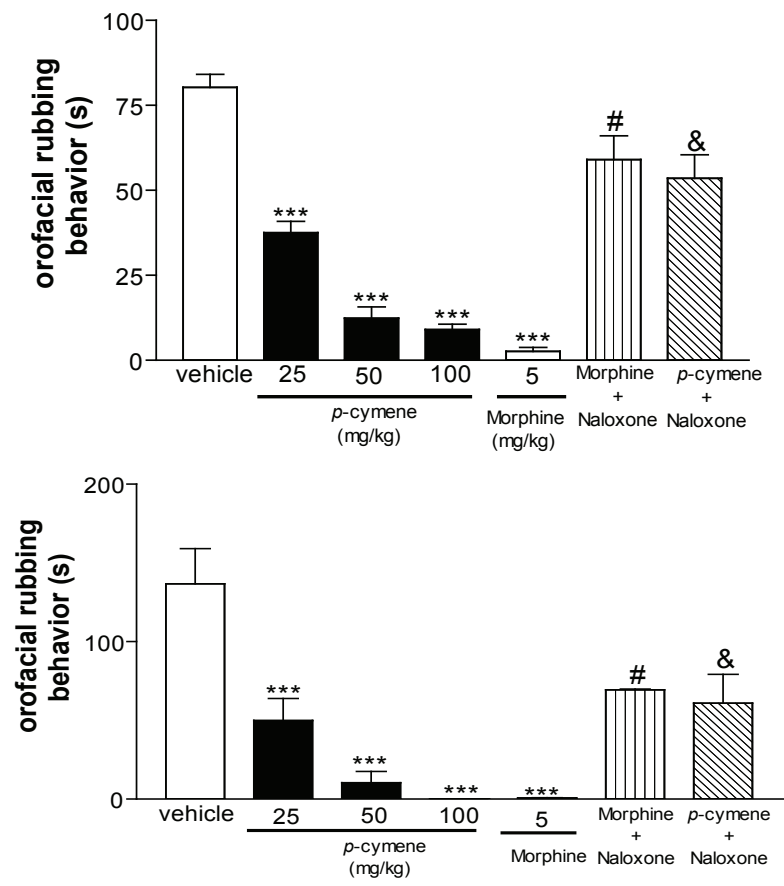

Figure 1. Effect of pretreatment of animals with vehicle, p-cymene $(25,50$ and $100 \mathrm{mg} / \mathrm{kg})$ or morphine $(5 \mathrm{mg} / \mathrm{kg})$ in the nociception induced by formalin. A indicates the first phase ( 0 to $5 \mathrm{~min}$ ) and $\mathrm{B}$ the second phase (15 to $40 \mathrm{~min}$ ) of formalin test $* * * p<0.001$ represents significant differences when compared to the control group (ANOVA followed by Dunnett). ${ }^{*} p<0.001$ indicates significant difference compared with morphine and ${ }^{\&} p<0.001$ compared with the $p$-cymene (100 mg/kg), (ANOVA followed by Tukey).

\section{Capsaicin test}

According to Figure 2, the pretreatment with $p$-cymene caused a statistically significant decrease $(p<0.001)$ of nociceptive behavior induced by administration of capsaicin at all doses $(25,50$, and 100 $\mathrm{mg} / \mathrm{kg}$ ). The effect of the highest dose was similar to morphine.

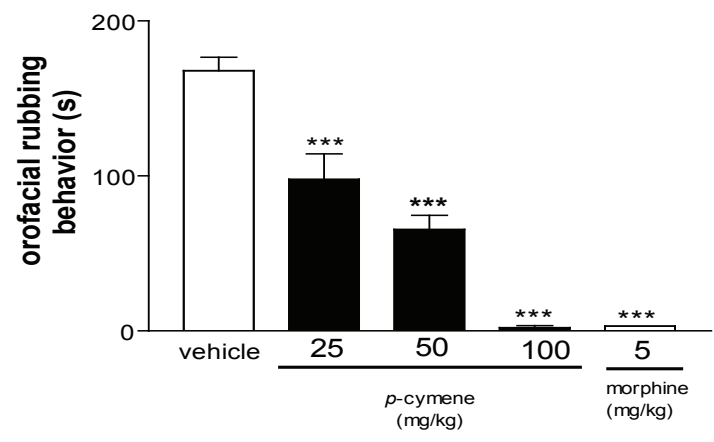

Figure 2. Effect of pretreatment of animals with vehicle, $p$-cymene $(25,50$ and $100 \mu \mathrm{g} / \mathrm{kg})$ or morphine $(5 \mathrm{mg} / \mathrm{kg})$ in the nociception induced by injection of capsaicin $(20 \mu \mathrm{L})$ in the orofacial region $(\mathrm{n}=8)$. ${ }^{* * *} p<0.001$ represents significant differences when compared to the control group (ANOVA followed by Dunnett).

\section{Glutamate test}

Systemic treatment of animals with $p$-cymene, at doses of 25,50 , and $100 \mathrm{mg} / \mathrm{kg}$ significantly reduced the nociception induced by administration of glutamate in the upper lip (Figure 3).

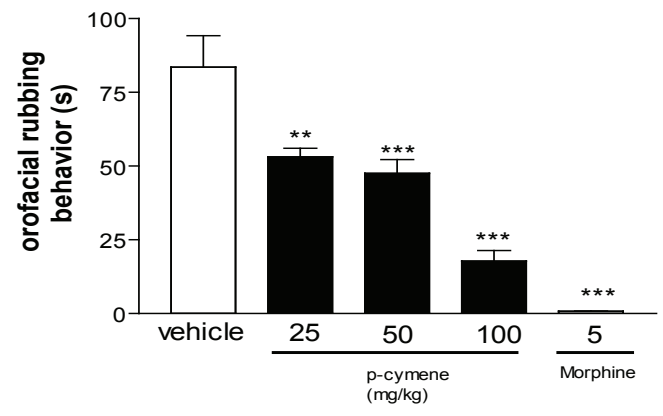

Figure 3. Effect of pretreatment of animals with vehicle, $p$-cymene $(25,50$ and $100 \mathrm{mg} / \mathrm{kg})$ in the nociception induced by injection of glutamate $(40 \mu \mathrm{L} / 25 \mathrm{mM})$ in the orofacial region $(\mathrm{n}=8) .{ }^{* *} p<0.01 * * * p<0.001$ represents significant differences when compared to the control group (ANOVA followed by Dunnett). 


\section{Rota-rod test}

Pretreatment of mice with $p$-cymene $(25,50$, and $100 \mathrm{mg} / \mathrm{kg}$ ) or vehicle did not induce changes in motor performance, since the animals remained on the rotating rod for $180 \mathrm{~s}$ at 30,60 , and $120 \mathrm{~min}$ (data not shown in figure). As expected, diazepam $(1.5 \mathrm{mg} / \mathrm{kg})$, a CNS depressant drug, reduced the latency time of falling at 30,60 , and $120 \mathrm{~min}$.

\section{Discussion}

This study demonstrated the antinociceptive effect of $p$-cymene by behavioral tests of nociception (formalin, capsaicin, and glutamate tests) in mice. The use of formalin in the orofacial region induces a biphasic nociceptive response (Luccarini et al., 2006). The first phase (0-5 $\mathrm{min})$ corresponds to the direct stimulation of nociceptors, predominantly $\mathrm{C}$ fibers, with the participation of substance $\mathrm{P}$, bradykinin, and glutamate (Shibata et al., 1989). This phase is only sensitive to analgesics acting on the CNS (Hunskaar et al., 1985). The first phase is followed by an interphase, which lasts about fifteen minutes and results from active inhibition of the excitability of nociceptors (Tjolsen et al., 1992). The second phase, which starts twenty-one min after formalin injection, is derived from two components: central sensitization of nociceptors and second order neurons, and the action of inflammatory mediators such as histamine, serotonin (5-HT), bradykinin, and prostaglandins released as a result of tissue injury (Henry et al., 1999). This second phase of nociception could be inhibited by both NSAID and opioid drugs (Hunskaar et al., 1985). The results of the present study showed that $p$-cymene significantly reduced the nociceptive behavior in the $1^{\text {st }}$ and $2^{\text {nd }}$ phases of the formalin test, suggesting therefore an action in both neurogenic and inflammatory pain. It was also verified that the non-selective opioid antagonist naloxone reversed the antinociceptive effect of $p$-cymene (100 $\mathrm{mg} / \mathrm{kg}$ ), suggesting an effect mediated by the opioid system.

Just as formalin, capsaicin is also an important irritant used to induce nociception. Capsaicin is used as a pharmacological tool for the study of nociception through direct activation of nociceptive fibers, especially type C (Sakurada et al., 1992). Capsaicin applied to skin, muscle, and other tissues has been shown to produce inflammation, to activate and to sensitize trigeminal and spinal small-diameter nociceptive afferents, as well as dorsal horn neurons. It also evokes nociceptive behavior in animals and intense pain, hyperalgesia, and referred pain in humans ( $\mathrm{Hu}$ et al., 2005; Lam et al., 2009a; Lam et al., 2009b).
The activation of nociceptors by capsaicin occurs through its binding to vanilloid receptors (TRPV1), which induces the influx of cations producing depolarization and excitation of neurons that cause the release of neuropeptides such as tachykinins, substance $\mathrm{P}$, calcitonin gene-related peptide, excitatory amino acids (aspartate and glutamate), nitric oxide, and proinflammatory mediators from the peripheral terminals (Sakurada et al., 1992). In this context, the antinociceptive effect observed for $p$-cymene in the capsaicin test may be a result of its possible inhibition of neurotransmitters involved in activation of sensory fibers responsible for transmission of nociceptive stimuli.

A number of monoterpenes have also been described as agonists or antagonists of different members of the TRPV channel family (Xu et al., 2005; 2006; Vogt-Eisele et al., 2007). The ability of camphor, a naturally occurring monoterpene produced by Camphor Laurel (Cinnamomum camphora), to modulate sensations of warmth in humans has been attributed to its ability to activate TRPV3 (Moqrich et al., 2005). TRPV3 is expressed in keratinocytes, the dorsal root ganglia, the brain, and spinal cord (Vogt-Eisele et al., 2007). It has been implicated in hyperalgesia, inflamed tissues, and possibly skin sensitization (Xu et al., 2005). Vogt-Eisele et al. (2007) demonstrated that some of the effects described for the terpenoids may be related to the activation of vanilloid receptors. The mechanism of action of camphor, menthol, thymol, and carvacrol, for example, is related to activation of TRPV3 receptors. $p$-Cymene did not significantly activate these receptors.

Glutamate is present in both central and peripheral terminals of trigeminal and dorsal root ganglion neurons. Noxious stimulation of primary afferent fibers results in the release of glutamate from the peripheral as well as central terminals of trigeminal and spinal afferent fibers (Keast \& Stephensen, 2000; Lam et al., 2005). In addition, glutamate injection into the rat masseter muscle or temporomandibular joint (TMJ) reflexly evokes a dose-dependent increase in jaw muscle electromyographic (EMG) activity (Cairns et al., 1998; Cairns et al., 2001a; Cairns et al., 2001b, Cairns et al., 2002) and central sensitization of trigeminal brainstem nociceptive neurons (Lam et al., 2009b). Similarly, glutamate injection into the human masseter muscle causes pain and mechanical hyperalgesia that may be attenuated by co-injection of a NMDA receptor antagonist (Cairns et al., 1998).

This nociceptive response caused by glutamate seems to involve peripheral, spinal, and supra-spinal sites, and its action is mediated by NMDA ( $N$-methylD-aspartate) and non-NMDA receptors (Beirith et al., 2002). Several studies have demonstrated that 
the excitatory amino acid receptors are involved in nociceptive primary afferent transmission, both in the development and maintenance of painful response (Coggeshall \& Carlton, 1997). Thus, the suppression of glutamate-induced nociception by $p$-cymene treatment can be associated with its interaction with the glutamatergic system (Ferreira et al., 1999). Batista et al. (2008) demonstrated that linalool, a monoterpene compound prevalent in the essential oils of various aromatic plant species, possesses antinociceptive properties in mice. This effect involves peripheral and spinal sites of action and seems to be mediated by interaction with ionotropic glutamatergic-dependent mechanisms, via NMDA receptors.

Previous studies have suggested that the CNS depression and the nonspecific muscle relaxation effect can reduce the response of motor coordination and might invalidate the behavior tests' results (Almeida et al., 2004; De Sousa et al., 2006). Our results revealed that all mice treated with $p$-cymene, at the doses evaluated, did not have any performance alteration in the Rotarod test. In addition, visually as well, there has been no interference with motor coordination of animals, thus eliminating a nonspecific muscle-relaxing effect of $p$-cymene.

\section{Conclusions}

Based on our results, the monoterpene $p$-cymene proved to have antinociceptive activity that does not interfere with motor coordination of animals, and this pharmacological action may modulate both neurogenic and inflammatory pain. Additionally, it seems, at least in part, that the antinociceptive action of $p$-cymene involves the opioid system. These results suggest and support the use of $p$-cymene as a promising substance for the management of orofacial pain; however, further studies are necessary to prove its mechanism of action.

\section{Acknowledgments}

This work was supported by the Fundação de Apoio à Pesquisa e à Inovação Tecnológica do Estado de Sergipe [grant number 019.203.00860/2009-6] and Conselho Nacional de Desenvolvimento Científico e Tecnológico, Brazil. The authors thank Richard Berger for editing the English of the manuscript.

\section{References}

Almeida RN, Motta SC, Faturi CB, Catallani B, Leite JR 2004. Anxiolytic-like effects of rose oil inhalation on the elevated plus-maze test in rats. Pharmacol Biochem Behav 77: 361-364.

Barros VM, Seraidarian PI, Côrtes MIS, Paula LV 2009
The impact of orofacial pain on the quality of life of patients with temporomandibular disorder. J Orofac Pain 23: 28-37.

Batista PA, Werner MFP, Oliveira EC, Burgos L, Pereira P, Brum LF, Santos AR 2008. Evidence for the involvement of ionotropic glutamatergic receptors on the antinociceptive effect of (-)-linalool in mice. Neurosci Lett 440: 299-303.

Beirith A, Santos AR, Calixto JB 2002. Mechanisms underlying the nociception and paw oedema caused by injection of glutamate into the mouse paw. Brain Res 924: 219-228.

Bispo MD, Mourão RHV, Franzotti EM, Bomfim KBR., Arrigoni-Blank MF, Moreno MPN, Marchioro M, Antoniolli AR 2001. Antinociceptive and antiedematogenic effects of the aqueous extract of Hyptis pectinata leaves in experimental animals. $J$ Etnopharmacol 76: 81-86.

Cadet R, Aigouv L, Woda A 1993. Sustained hyperalgesia can be induced in the rat by a single formalin injection and depends on the initial nociceptive inputs. Neurosci Lett 156: 43-46.

Cairns BE, Sessle BJ, Hu JW 1998. Evidence that excitatory amino acid receptors within the temporomandibular joint region are involved in the reflex activation of the jaw muscles. J Neurosci 18: 8056-8064.

Cairns BE, Sessle BJ, Hu JW 2001a. Characteristics of glutamate-evoked temporomandibular joint afferent activity in the rat. $J$ Neurophysiol 85: 2446-2454.

Cairns BE, Hu JW, Arendt-Nielsen L, Sessle BJ, Svensson P 2001b. Sex-related differences in human pain and rat afferent discharge evoked by injection of glutamate into the masseter muscle. J Neurophysiol 86: 782791.

Cairns BE, Gambarota G, Svensson P, Arendt-Nielson L, Berde CB 2002. Glutamateinduced sensitization of rat masseter muscle fibers. Neuroscience 109: 389-399.

Coggeshall RE, Carlton SM 1997. Receptor localization in the mammalian dorsal horn and primary afferent neurons. Brain Res Rev 24: 28-66.

De Sousa DP, Gonçalves JCR, Quintans-Júnior LJ, Cruz JS, Araújo DAM, Almeida RN 2006. Study of anticonvulsant effect of citronellol, a monoterpene alcohol, in rodents. Neurosci Lett 401: 231-235.

Dionne RA 2001. Pharmacologic advances in orofacial pain: from molecules to medicine. J Dent Educ 65: 13931403.

Ferreira J, Santos ARS, Calixto JB 1999. The role of systemic, spinal and supraspinal L-argininenitric oxide-cGMP pathway in thermal hyperalgesia caused by intrathecal injection of glutamate in mice. Neuropharmacol 38 : $835-842$

Galeoti N, Mannelli LC, Mazzanti G, Bartolini A, Ghelardini C 2002. Menthol: a natural analgesic compound. Neurosci Lett 322: 145-148.

Gonçalves JCR, Oliveira FS, Benedito RB, Sousa DP, Almeida RN, Araújo DAM 2008. Antinociceptive activity of (-)-carvone: evidence of association with decreased peripheral nerve excitability. Biol Pharm Bull 31: 1017-1020.

Henry JL, Yaspal K, Picher GM, Chabot JG, Coderre TJ 
1999. Evidence for tonic activation of NK-1 receptors during the second phase of the formalin test in the Rat. J Neurosci 19: 6588-6598.

Hu JW, Fiorentino PM, Cairns BE, Sessle BJ 2005. Capsaicininduced inflammation within temporomandibular joint involves VR-1 receptor mechanisms. Oral Biosci Med 4: 241-248.

Hunskaar S, Fasmer OB, Hole K 1985. Formalin test in mice, a useful technique for evaluating mild analgesics. $J$ Neurosci Methods 14: 69-76.

Keast JR, Stephensen TM 2000. Glutamate and aspartate immunoreactivity in dorsal root ganglion cells supplying visceral and somatic targets and evidence for peripheral axonal transport. J Comp Neurol 424: 577-587.

Lam DK, Sessle BJ, Cairns BE, Hu JW 2005. Neural mechanisms of temporomandibular joint and masticatory muscle pain: a possible role for peripheral glutamate receptor mechanisms. Pain Res Manag 10: 145-152.

Lam DK, Sessle BJ, Hu JW 2009a. Glutamate and capsaicin effects on trigeminal nociception I: activation and peripheral sensitization of deep craniofacial nociceptive afferents. Brain Res 1251: 130-139.

Lam DK, Sessle BJ, Hu JW 2009b. Glutamate and capsaicin effects on trigeminal nociception II: activation and central sensitization in brainstem neurons with deep craniofacial afferent input. Brain Res 1253: 48-59.

Lipton JA, Ship JA, Larach-Robinson D 1993. Estimated prevalence and distribution of reported orofacial pain in the United States. JADA 124: 115-121.

Luccarini P, Childeric A, Gaydier AM, Volsin D, Dallel R 2006. The orofacial formalin test in the mouse: a behavioral model for studying physiology and modulation of trigeminal nociception. J Pain 7: 908914.

Melo MS, Sena LCS, Barreto FJN, Bonjardim LR, Almeida JRGS, Lima JT, De Sousa DP, Quintans-Júnior LJ 2010. Antinociceptive effect of citronellal in mice. Pharm Biol 4: 411-416.

Moqrich A, Hwang SW, Earley MJ, Petrus J, Murray AN, Spencer KS, Andahazy M, Story GM, Patapoutian A 2005. Impaired thermosensation in mice lacking TRPV3, a heat and camphor sensor in the skin. Science 307: 1468-1472.

Oliveira FA, Costa CLS, Chaves MH, Almeida FRC, Cavalcante IJM, Lima AF, Lima-Júnior RCP, Silva RM, Campos AR, Santos FA, Rao VSN 2005. Attenuation of capsaicin-induced acute and visceral nociceptive pain by alpha- and beta-amyrin, a triterpene mixture isolated from Protium heptaphyllum resin in mice. Life Sci 77: 2942-2952.

Otuki MF, Lima FV, Malheiros A, Filho VC, Monache FDM, Yunes RA, Calixto J 2001. Evaluation of the antinociceptive action caused by ether fraction and a triterpene isolated from resin of Protium kleinii. Life Sci 69: 2225-2236.

Peana AT, Marzocco S, Popolo A, Pinto A 2006. (-)-Linalool inhibits in vitro NO formation: Probable involvement in the antinociceptive activity of this monoterpene compound. Life Sci 78: 719-723.

Pellisier T, Pajor J, Dalle R 2002. The orofacial capsaicin test in rats: effects of different capsaicin concentrations and morphine. Pain 96: 81-87.

Quintans-Júnior LJ, Melo MS, De Sousa DP, Araújo AAS, Onofre ACS, Gelain DP, Gonçalves JCR, Araújo DAM, Almeida JRGS, Bomjardim LR 2010. Antinociceptive activity of citronellal in formalin-, capsaicin- and glutamate-induced orofacial nociception in rodents and its action on nerve excitability. J Orofac Pain 24: 305-312.

Ramezani M, Hosseinzadeh H, Samizadeh S 2004. Antinociceptive effects of Zataria multiflora Boiss fractions in mice. $J$ Ethonopharmacol 91: 167-170.

Sakurada T, Katsumata K, Tan-no K, Saturada S, Kisara K 1992. The capsaicin test in mice for evaluating tachykinin antagonists in the spinal cord. Neuropharmacol 31: 1279-1285.

Sessle BJ 1987. The neurobiology of facial and dental pain: present knowledge, future directions. J Dent Res 66: 962-981.

Shibata M, Ohkubo T, Takahashi H, Inoki R 1989. Modified formalin test: characteristic biphasic pain response. Pain 38: 347-352.

Siani AC, Garrido IS, Carvalho ES, Ramos MFS 1999. Evaluation of anti-inflammatory-related activity of essential oils from the leaves and resin of species of Protium. J Ethnopharmacol 66: 57-69.

Tjolsen A, Berge OG, Hunskaar S, Rosland JH, Hole K 1992. The formalin test: an evaluation of the method. Pain 51: 5-17.

Vogt-Eisele AK, Weber K, Sherkheli MA, Panten J, Gisselmann G, Hatt H 2007. Monoterpenoid agonists of TRPV3. Br J Pharmacol 151:530-540.

Xu HX, Blair NT, Clapham DE 2005. Camphor activates and strongly desensitizes the transient receptor potential vanilloid subtype 1 channel in a vanilloid-independent mechanism. J Neurosci 25: 8924-8937.

Xu HX, Delling M, Jun JC, Clapham DE 2006. Oregano, thyme and clove-derived flavors and skin sensitizers activate specific TRP Channels. Nat Neurosci 9: 628635.

Zimmermann M 1983. Ethical guidelines for investigations of experimental pain in conscious animals. Pain 16: $109-110$

\section{*Correspondence}

Leonardo Rigoldi Bonjardim

Departamento de Fisiologia, Universidade Federal de Sergipe

49100-000 São Cristóvão-SE, Brazil

lbonjardim@ufs.br

Tel.: +557921056645

Fax: +55 7921056494 